\title{
MAKE A MAS MAS TOURIST VILLAGE INDEPENDEN WITH ACCOUNTING EMKM APPLICATION
}

\author{
Lalu Takdir Jumaidi ${ }^{1}$, Iman Waskito², Satarudin ${ }^{3}$, Bambang $^{4}$ \\ Program Studi Akuntansi Fakultas Ekonomi dan Bisnis Universitas Mataram \\ takdirjumaidi@yahoo.com
}

\begin{abstract}
ABSTRAK
Tujuan dari pengabdian ini adalah, 1 . Memberikan pengetahuan/wawasan tentang kewirausahaan dan pengembangan Desa Wisata kepada masyarakat desa lebih khusus pada wirausahawan desa, perangkat desa dan Bumdes tentang Strategi pengembangan kewirausahaan dan pengembangan Desa Wisata. 2. Menemukan strategi yang efektif dan dapat melakukan pengelolaan keuangan yang baik, sehingga usaha desa wisata MasMas dapat berjalan dengan lebih "mandiri". Sesuai dengan hasil evaluasi lapangan, tehnis yang paling efektif dikaukannya penyuluhan dan bimbingan intensif tentang pengetahuan strategi pengembangan desa wisata dan implementasi akuntansi desa wisata. Adapun hasil penyuluhan dan bimbingan yang diberikan adalah telah diperoleh rumusan sederhana tentang strategi pengembangan desa wisata, yaitu terbentuknya kesadaran masyarakat akan pentingnya partisipasi dan kerjasama semua pihak untuk membangun sinergitas dalam pengembangan Desa Wisata dan masyarakat desa semakin faham akan manfaat dari ilmu akuntansi yang diterapkan dalam aktifitas Desa Wisata, serta wujudnya motifasi untuk menghidupkan wirausaha Budi Daya Sapi. Pemahaman itu diperoleh dengan tehnis langsung mempraktkkan ilmu akuntansi hingga menghasilkan laporan keuangan desa wisata.
\end{abstract}

Kata kunci: Desa Wisata, berkelanjutan, potensi desa wisata, akuntansi

\begin{abstract}
Lunching on the establishing and developing "a thousand villages' destinations" is possible due to the unique potential "resources", such as local languages, literature opuses, traditional songs and dances, high value of handicrafts, certain unique and nature production modes, the available of beautiful unique cultures, challenging with its historical background, sacred places and identified with spirituality. These potencies can support the establishing and developing " $a$ thousand villages' destinations". For the sake of practice on finding out and evaluating villages' potencies which can be established to be villages'
\end{abstract}


destinations. The establishment and development made suite to stakeholders. Therefore, useful common accountant knowledge is going to be introduced in hope that it could be used to make standard report, control and make decision, and develop business. Despite promoting through global internet, the establishing and developing can also be done by having competition on destinations' packet. It is made and suited with other destinations so that it could create more innovating and interesting products of destinations' packet.

Key words: Tourism Villages Destination, Tourism Village Potencies, Accounting.

\section{PENDAHULUAN}

Pengabdian ini adalah meneruskan pengabdian di Desa Mas-mas tahun lalu, salah satu Desa wisata yang ada di NTB yang terletak di Batu Kliang di pedalaman Lombok Tengah. Pengabdian periode ini mengarahkan Pembnagunan Desa Wisata dengan menemukan potensi-potensi alam yang dapat menjadi obyek wisata unggulan, dengan pengenalan pembukuan sederhana. Mengingat hasil pengamatan akan potensi SDM dan Sumber Daya Alam yang sangat potensial, Pengabdian saat ini mengarah pada penentuan unit-unit UKM. Unit unggulan wirausaha itu salah satunya adalah Budi daya sapi. Mengingat kondisi pengelolaan keungan belum memadai dan sistem pemasaran yang masih belum efektif, maka harapannya aktifitas akuntansi UMKM yang dulunya masih menggunakan pencatatan biasa, akan dikenalkan dengan SAK UMKM, dengan harapan nantinya dapat menjadi lebih baik dan mandiri.

Kondisi ini kemudian diberikan sentuhan motifasi untuk terus berinovasi dan berkreatifitas, terjalinnya "kerjasama sinergitas" anatara masyarakat, perangkat desa, pemerintah dan sthacholder yang lain, maka potensi ini dapat menjadi potensi besar untuk membuka "Desa Wisata".

Berbagai permasalahan yang dihadapi oleh masyarakat desa Mas-mas, secara umum adalah belum adanya sosialisasi dan pengenalan sistem keuangan desa yang konsisten dengan penrapan SAK EMKM. Jadi dapat disimpulkan beberapa hal yang menjadi pemicu diperlukannya pengabdian ini adalah:

a. Dirasakan "Pentingnya penyuluhan tehnis yang berkelanjutan tentang pengembangan kewirausahaan khususnya Budi Daya sapi berbasis 


\section{Jurnal ABDIMAS INDEPENDEN}

Vol. 2, No. 1, Mei 2021

kepariwisataan" perlu terus ditingkatkan mengingat Potensi yang tersedia.

b. Masih dirasakan "kurangnya pengenalan pengelolaan keuangan desa wisata yang sederhana dengan pendekatan SAK EMKM".

c. Masih "belum optimalnya penerapan pengembangan strategi pemasaran dengan memanfaatkan sistem jaringaninternet" sebagai tempat informasi global untuk mengenalkan \& mempromoskan potensi wisata desa.

d. Masih perlu terus "menjaga dan mengembangkan" terbentuknya motifasi yang tinggi untuk melakukan pengembangan usaha ke bidang pariwisata, khususnya UMKM Budi Daya Sapi

Berdasarkan uraian atas analisis situasi di atas, maka rumusan masalahnya adalah: "Bagaimana memberikan pengetahuan \& bimbingan Kewirausahaan di bidang Budi Daya Sapi dan memberikan pengetahuan tentang AkuntansiEMKM, untuk menunjang pengembangan Desa Wisata yang mandiri. Adapun tujuan pengabdian ini adalah: memberikan penyuluhan kepada masyarakat khususnya wirausaha Budi daya Sapi dan dengan memperkenalkan SAK UMKM dalam hubungannya dengan pengembangan Usaha Desa Wisata, penyuluhan tentang pengembangan kewirausahaan kuhususnya Budi Daya Penggemukan sapi dengan memanfaatkan sumber daya yang ada, Memperkenalkan penerapan sistem dan siklus akuntansi SAK EMKM untuk dapat menghasilkan informasi akurat tentang besarnya biaya produksi, harga pokok produksi, tingkat pendapatan dan keuntungan yang diperoleh serta perkembangan nilai aset dan kewajiban serta modal yang dimilki.

Dengan adanya penyuluhan dibidang pengembangan kewirausahaan khususnya budi daya dan penerapan akuntansi berdasarkan SAK UMKM, serta strategi pemasaran terhadap usaha Wirausaha Pariwisata, maka masyarakat desa akan semakin mampu "Meningkatkan kualitas manajemen pengelolaan usaha sehingga mampu meningkatkan kinerja UMKM dan pengembangan jenis 
bidang usaha lainnya sehingga saling bersinergi dalam meningkatkan produktifitas Desa Wisata yang lebih mandiri"

\section{METODE KEGIATAN}

Metode yang digunakan dalam melakukan kegiatan ini adalah dengan penyuluhan tehnis Budi daya sapi dan penggemukan sapi dengan pemanfaatan limbahnya dan "pelatihan akuntansi UMKM". Pelatihan akuntansi dengan standar UMKM, disertai "pendampingan berkelanjutan" berupa konsultasi sampai pengusaha ini mampu mengimplementasikan akuntansi usaha mikronya. Pelaksanaan Kegiatan ini terdiri dari beberapa tahap, antara lain:

a. Tahap I Persiapan (Observasi)

Observasi dan persiapan dilakukan dalam rangka mempersiapkan segala sesuatu yang terkait dengan kegiatan pelatihan yang akan dilakukan. Persiapan tersebut antara lain: pembuatan modul yang akan dijadikan panduan dalam pelatihan, baik Tehnis budi daya sapi, penggemukan sapi dan proses pelaksanaan akuntansi standar EMKM.

b. Tahap II Pelaksanaan

1. Penyuluhan-Pelatihan (2 Minggu)

Pelatihan penyusunan akutansi yang bersatandarkan akuntansi UMKM dan Tehnis Budi Daya Sapi difasilitaskan oleh tim Pengabdian.

1. Pendampingan ( 2 bulan)

Setelah pelatihan, selanjutnya tim pengabdian yang telah dilakukan pendampingan. Pendampingan ini perlu dilakukan untuk memastikan para pemilik UKM telah mampu mewujudkan usaha usaha dengan baik dan mengimplementasikan akuntansi bersatandarkan UMKM.

c. Tahap III Evaluasi (Jangka waktu 1 bulan)

Pada tahap kedua ini, dilakukan evaluasi atas kegiatan 3 bulan sebelumnya. Selanjutnya tim melakukan penyusunan laporan 


\section{Jurnal ABDIMAS INDEPENDEN}

Vol. 2, No. 1, Mei 2021

\section{HASIL DAN PEMBAHASAN}

Berdasarkan hasil analisis, maka masyarakat telah mengelompokkan aspek-aspek yang dapat dikembangkan yakni aspek budidaya pertanian dan peternakan. Pada aspek pertanian, masyarakat berpendapat bahwa terdapat beberapa kegiatan dalam lingkup pertanian yang dapat dikembangkan sekaligus dapat dijadikan sebagai atraksi wisata tanpa menegenal masa. Seperti diketahui bahwa mata pencaharian utama penduduk desa adalah pertanian, sehingga hampir seluruh penduduk di desa tersebut tergantung kepada hasil pertanian. Kondisi ini tentuya sangat sinergi untuk membangun usaha Peternakan Budidaya Sapi.

\section{Membangun Kemandirian Desa Wisata Dengan Implementasi Akuntansi}

Untuk desa wisata yang yang operasionalnya adalah di bidang jasa maka akuntansi yang dijalankan dapat melakukan proses akuntansi yang lebih sederhana. Berikut disajikan bentuk akuntansi jasa dan akuntansi dagang:

Siklus Akuntansi usaha Jasa:

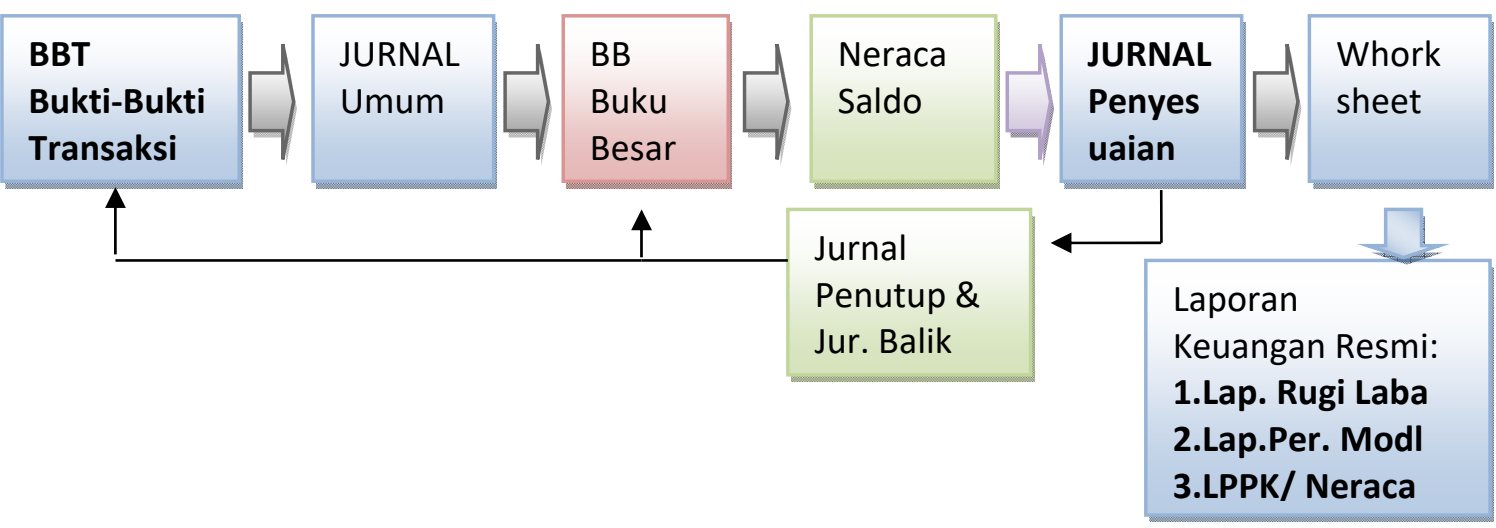

\section{a. Bukti Bukti Transaksi}

Seluruh aktifitas usaha/perusahaan yang dapat diukur dengan nilai mata uang dan memilki pengaruh terhadap keuangan perusahaan, maka transaksi itu dapat dicatat ke dalam bukti-bukti transaksi yang telah disiapkan

Bentuk dari bukti transaksi dapat dibedakan menjadi dua: 1. Bukti transaksi yang dibuat dan dikeluarkan dari perusahaan sendiri. Contohnya: Faktur Penjualan, Kwitansi, Bukti Kas Keluar/masuk, Nota debet, Giro, 2. Bukti transaksi yang 
diterima dari perusahaan lain. Contohnya: Faktur Pembelian, Invoice, Bukti Bank, SSP.

Bukti-bukti transaksi ini diarsip dan didokumentasikan dengan rapid teratur. Dapat diatur sesuai dengan tanggal transaksi, dapat diatur sesuai dengan aktifitas investasi dan aktfitas operasional. Dapat juga diarsip sesuai dengan kepentingan internal atau ekternal, dapat juga diarsip sesuai dengan departemen. Tergantung mana yang dianggap paling efektif sesuai dengan kondisi perusahaan.

\section{b. Jurnal}

Adapun bentuk jurnal adalah:

1. Jurnal umum, 2. Jurnal khusus, 3. Jurnal penyesuaian

Untuk Aktifitas jurnal, biasanya pada tingkat perusahaan jasa menggunakan jurnal umum, dan pada tingkat perusahaan dagang dan industri menggunakan jurnal khusus. Khusus penggunaan jurnal khusus akan sangat efektif ketika operasional perusahaan cukup variatif pada transaksi penjualan dan pembelian baik secara tunai dan kredit, serta aktifitas biaya yang sangat tinggi. Bentuk jurnal khusus yaitu: jurnal Penerimaan Kas, Pengeluaran kas, Penjualan danl Pembelian.

Untuk jurnal adjastman diperlukan ketika saat penyusunan laporan keuangan periodik. Fungsi dari jurnal penyesuaian adalah menarik dan mengakui transaksi asset maupun biaya dan pendapatan yang belum diakui dan akan diakui. Tehnik melakukan proses jurnal adalah: dari Format Logika Persamaan Akuntansi, $A=H+$ Modal $\{+$ Pendapatan - Biaya + Setoran - Prive $\}$. Seluruh komponen Aktiva diberikan simbul " $D$ " Seluruh elemen Hutang \& Modal diberi simbul "Kredit" yang letaknya di sebelah kiri. Adapun simbul Debet dan Kredit berfungsi untuk penempatan posisi awal \& tujuan melakukan penambabahan atau pengurangan. Jika kita lihat isi \& tahapan proses pengembangan persmaan

\begin{tabular}{|cccc|}
\cline { 2 - 3 } Debet & & $\underline{\text { Kredit }}$ \\
$\mathbf{A}$ & $=$ & $\mathbf{H}+$ Modal \\
$\mathbf{A}^{\prime}$ & $=$ & $\mathbf{H}^{\prime}+$ Modal' \\
Kas.Piutano.Persed. Perl & $=$ & Hutano + Modal (Pend-Riava+Setoran-Prive) \\
\hline
\end{tabular}




\section{Jurnal ABDIMAS INDEPENDEN}

Vol. 2, No. 1, Mei 2021

Contohnya Penerimaan Kas dari transaksi pendapatan tunai dan penerimaan Kas dari setoran, demikian pula penerimaan kas dari hasil pembentukan hutang dan modal, maka akan menambah Aset dalam bentuk Kas. Sebaliknya transaksi mengakibatkan pengurangan terhadap kas.

Dalam jurnal menggunakan penerapan simbul Debet dan kredit. Jika ada transaksi menambanh asset seperti di atas maka akan diltekakkan di posisi sama Debet, sebaliknya jika bersifat mengurangi asset maka rekening tersebut akan diletakkan di Kredit. Demikian pula untuk transaksi yang berhubungan dengan Pasiva, yaitu Hutang \& Modal. Jika aktifitasnya bersifat mengurangi Hutang \& Modal maka posisinya, diletakkan di Debet (berlawanan). Jika sifatnya sebalinya ada transaksi yang sifatnya menambah maka akan diletakaan di Kredit (sama)

Contoh jurnal dari aktifitas Desa Wisata:

\begin{tabular}{|c|l|l|l|}
\hline Tgl & \multicolumn{1}{|c|}{ Nama Rekening } & D & K \\
\hline $1 / 1$ & Kas & 50.000 .000 & \\
\hline & Modal & & 50.000 .000 \\
\hline & Diterima investasi dari modal DD & & \\
\hline $3 / 1$ & Kas & 20.000 .000 & \\
\hline & Hutang & & 20.000 .000 \\
\hline & Diterima Kas dari Hutang Bank & & \\
\hline $5 / 1$ & Perlengkapan & 2.000 .000 & \\
\hline & Kas & & 2.000 .000 \\
\hline & Dibayar perlengkapan & & \\
\hline $7 / 1$ & Peralatan & 12.000 .000 & \\
\hline & Kas & & 12.000 .000 \\
\hline & Dibayar Kas untuk Peralatan W & & \\
\hline $10 / 1$ & Infrastruktur (5 Th) & 12.000 .000 & \\
\hline & Kas & & 12.000 .000 \\
\hline & Dibayar biaya Infrastruktur & & \\
\hline $15 / 1$ & Kas & 7.500 .000 & \\
\hline & Pendapatan-Paket Wisata 1 (3 hari) & & 7.500 .000 \\
\hline & Diterima Pendapatan- P.W.1 & & \\
\hline $19 / 1$ & Kas & 5.500 .000 & \\
\hline & Pendapatan-Paket W. 2 (3 hari) & & 5.500 .000 \\
\hline & Diterima pendapatan dari Paket W.2 & & \\
\hline
\end{tabular}




\begin{tabular}{|l|l|l|l|}
\hline Tgl & \multicolumn{1}{|c|}{ Nama Rekening } & \multicolumn{1}{c|}{ D } & \multicolumn{1}{c|}{ K } \\
\hline 25 & Kas & 7.000 .000 & \\
\hline & Pendapatan Paket W. 3 (2 hari) & & 7.000 .000 \\
\hline & Diterima pendapatan dari PS. & & \\
\hline 30 & Biaya Listrik & 200.000 & \\
\hline & Kas & & 200.000 \\
\hline 30 & $\begin{array}{l}\text { Bibayar listrik untuk 1 bln } \\
\text { Kas Internet dan air lainnya }\end{array}$ & 300.000 & 300.000 \\
\hline \multicolumn{2}{|c|}{ Setelah kita selesai melakukan proses penjurnalan, maka langkah } \\
\hline
\end{tabular}

berikutnya memindahkan atau memposting setiap rekening yang ada di jurnal ke dalam Buku Besar masing-masing. Tehnik pengisian Buku Besar adalah sebagai berikut:

1. Dimulai dengan rekening Neraca yaitu Aktiva, Hutang dan Modal, 2. Mengisi rekening Rugi/Laba, yaitu rekening Pendapatan dan Biaya.

\section{Contoh Buku Besar dari aktifitas jurnal Desa Wisata.}

BB: Kas

No. Rek. 101

\begin{tabular}{|l|l|l|l|c|}
\hline Tgl & Keterangan & Debet & Kredit & Saldo D \\
\hline $1 / 1$ & & 50.000 .000 & & 50.000 .000 \\
$3 / 1$ & & 20.000 .000 & & 70.000 .000 \\
$5 / 1$ & & & 2.000 .000 & 68.000 .000 \\
$7 / 1$ & & & 12.000 .000 & 56.000 .000 \\
$10 / 1$ & & 12.000 .000 & 44.000 .000 \\
$15 / 1$ & & 7.500 .000 & & 51.500 .000 \\
$19 / 1$ & & 5.500 .000 & & 57.000 .000 \\
$25 / 1$ & & 7.000 .000 & & 64.000 .000 \\
$31 / 1$ & & & 200.000 & 63.800 .000 \\
$31 / 1$ & & & 300.000 & $\mathbf{6 3 . 5 0 0 . 0 0 0}$ \\
\hline
\end{tabular}

BB: Perlengkapan

No. Rek. 102

\begin{tabular}{|l|l|l|l|c|}
\hline Tgl & Kereterangan & D & K & Saldo \\
\hline & & 2.000 .000 & & 2.000 .000 \\
& Adj & & 200.000 & 1.800 .000 \\
\hline
\end{tabular}

BB: Peralatan

No. Rek. 103

\begin{tabular}{|l|l|l|l|c|}
\hline Tgl & Keterangan & D & K & Saldo \\
\hline & & 12.000 .000 & & $\mathbf{1 2 . 0 0 0 . 0 0 0}$ \\
\hline & Adj Umur 5 Tahun & & & \\
\hline
\end{tabular}

BB: Akkumulasi Peny. Peralatan

No. Rek. 104

\begin{tabular}{|l|l|l|l|c|}
\hline Tgl & Ketrangan & D & K & Saldo \\
\hline & Adj & 200.000 & & $\mathbf{2 0 0 . 0 0 0}$ \\
\hline
\end{tabular}

BB: Infrastruktur

No. Rek. 105 


\section{Jurnal ABDIMAS INDEPENDEN}

Vol. 2, No. 1, Mei 2021

\begin{tabular}{|c|c|c|c|c|}
\hline Tgl & Keterangan & D & K & Saldo \\
\hline & & 12.000 .000 & & 12.000 .000 \\
\hline & Adj & & 200.000 & $\mathbf{1 1 . 8 0 0 . 0 0 0}$ \\
\hline
\end{tabular}

\begin{tabular}{ll}
\hline BB: Hutang No. Rek. 201 & No1
\end{tabular}

\begin{tabular}{|c|c|c|c|c|}
\hline Tgl & Keterangan & D & K & Saldo \\
\hline & & 20.000 .000 & & $\mathbf{2 0 . 0 0 0 . 0 0 0}$ \\
\hline
\end{tabular}

BB: Modal

\begin{tabular}{|c|l|l|l|c|}
\hline Tgl & Keterangan & D & K & Saldo \\
\hline $1 / 1$ & & & & $\mathbf{5 0 . 0 0 0 . 0 0 0}$ \\
\hline
\end{tabular}

BB: Prive

\begin{tabular}{|l|l|l|l|l|}
\hline Tgl & Keterangan & D & K & Saldo \\
\hline & & & & \\
\hline
\end{tabular}

BB: Pendapatan

\begin{tabular}{|c|l|c|c|c|}
\hline Tgl & \multicolumn{1}{|c|}{ Keterangan } & D & K & \multicolumn{1}{|c|}{ Saldo K } \\
\hline 15 & Pendap.Pak.W.2(3hr) & & 5.500 .000 & 5.500 .000 \\
19 & Pendap.Pak.W.3(2 hr) & & 7.000 .000 & 12.500 .000 \\
25 & Pendap.Pak.W.1(3 hr) & & 7.500 .000 & $\mathbf{2 0 . 0 0 0 . 0 0 0}$ \\
& Saldo & & & \\
\hline
\end{tabular}

BB: Biaya Perlengkapan

No. Rek. 501

\begin{tabular}{|c|l|c|c|c|}
\hline Tgl & \multicolumn{1}{|c|}{ Keterangan } & D & K & Saldo \\
\hline & Adj & 200.000 & & $\mathbf{2 0 0 . 0 0 0}$ \\
\hline
\end{tabular}

BB: Biaya Peny. Peralatan

No. Rek. 502

\begin{tabular}{|c|l|c|c|c|}
\hline Tgl & \multicolumn{1}{|c|}{ Keterangan } & D & K & Saldo D \\
\hline & Adj & 200.000 & & $\mathbf{2 0 0 . 0 0 0}$ \\
\hline
\end{tabular}

BB: Biaya Infrastruktur

No. Rek. 503

\begin{tabular}{|c|c|c|c|c|}
\hline Tgl & Keterangan & D & K & Saldo D \\
\hline & & 200.000 & & $\mathbf{2 0 0 . 0 0 0}$ \\
\hline
\end{tabular}

BB: Biaya Listrik

No. Rek. 504

\begin{tabular}{|c|c|c|c|c|}
\hline $\mathrm{Tgl}$ & Keterangan & D & K & Saldo D \\
\hline 30 & & 200.000 & & $\mathbf{2 0 0 . 0 0 0}$ \\
\hline
\end{tabular}

BB: Biaya Telpon, air dan internet

No. Rek. 505

\begin{tabular}{|c|c|c|c|c|}
\hline $\mathrm{Tgl}$ & Keterangan & D & K & Saldo D \\
\hline $30 / 1$ & & 300.000 & & $\mathbf{3 0 0 . 0 0 0}$ \\
\hline
\end{tabular}

a. Neraca Saldo 


\section{Desa Wisata Mas Mas}

NERACA SALDO

Per 1 Agustus 2019

\begin{tabular}{|c|l|r|r|}
\hline No. Rek & \multicolumn{1}{|c|}{ Nama Rekening } & \multicolumn{1}{c|}{ Debet } & \multicolumn{1}{c|}{ Kredit } \\
\hline 101 & Kas & 63.500 .000 & \\
\hline 102 & Perlengkapan & 2.000 .000 & \\
\hline 103 & Peralatan & 12.000 .000 & \\
\hline 104 & Akkumulasi Peny. Peralatan & & \\
\hline 105 & Infrastruktur & & 20.000 .000 \\
\hline 201 & Hutang & & 50.000 .000 \\
\hline 301 & Modal & & 20.000 .000 \\
\hline 401 & Pendapatan Paket 1,2,3 & & \\
\hline 501 & Biaya Perlengapan & & \\
\hline 502 & Biaya Peralatan & & \\
\hline 503 & Biaya Infrastruktur & & \\
\hline 504 & Biaya Listrik & $\mathbf{9 0 . 0 0 0 . 0 0 0}$ & $\mathbf{9 0 . 0 0 0 . 0 0 0}$ \\
\hline 505 & Biaya Internet, telp dan air & & \\
\hline & & & \\
\hline
\end{tabular}

\section{b. Penyesuaian}

\begin{tabular}{|l|l|l|l|}
\hline No.Rek & Nama Rekening & Debet & Kredit \\
\hline 502 & $\begin{array}{l}\text { Biaya Perlengkapan } \\
\text { Perlengkapan } \\
\text { (Penyesuaian) }\end{array}$ & 200.000 & 200.000 \\
\hline 503 & $\begin{array}{l}\text { Biaya Infrastruktur } \\
\text { Infrastruktur } \\
\text { (Penyesuaian) }\end{array}$ & 200.000 & 200.000 \\
\hline 504 & $\begin{array}{l}\text { Biaya Peny. Peralatan } \\
\text { Akk. Peny. Peralatan } \\
\text { (Penyesuaian) }\end{array}$ & 200.000 & 200.000 \\
\hline
\end{tabular}

\section{c. Neraca Lajur \& Laporan Perubahan Posisi Keuangan Di Lampiran}

Dapat dilihat dan dipelajari pada halaman berikunya. Neraca Lajur berisi tentang laporan lengkap dari Neraca Saldo, Ayat Penyesuaian, Neraca Saldo Setelah Penyesuaian, Laporan Rugi Laba dan Laporan Peubahan Posisi Keuangan atau Neraca 


\section{Jurnal ABDIMAS INDEPENDEN}

Vol. 2, No. 1, Mei 2021

\section{SIMPULAN DAN SARAN}

\section{Kesimpulan}

Dalam melakukan pengebangan Desa Wisata, beberapa hal yang perlu dilakukan adalah:

1. Mengerakkan masyarakat desa secara bersama dengan cara membuka wawasan mereka tentang manfaat posisitif yang luar biasa dari hidup dan berkembangnya Desa Wisata yang semakin maju.

2. Terciptanya sinergi yang kuat anatara semua elemen yang ada yang saling terkait antara satu dengan yang lain

3. Paket-paket kredit ringan untuk program pengembangan desa wisata.

4. Diperlukannya Strategi pengembnagan desa wisata yang berkesinambungan, dengan melakukan analisis dan diagnosis secara lebih mendalam, sehingga didapatkan pemilihan strategi yang paling tepat dan implementasi strategi yang benar dalam mencapai visi, misi dan tujuan.

5. Setiap akhir tahun selalu dilakukan evaluasi terhadap strategi yang telah di jalankan, sehingga dapat diketahui apakah strategi telah tepat, atau tidak. Jika belum sesuai, maka perlu perbaikan strategi, sehingga terciptalah pengembangan desa wisata.

6. Diperlukannya pemahaman dan penerapan akuntansi sederhana dalam aktifitas desa wisata. Tujuannya agar terwujud sinergitas yang lebih baik, dan dapat mengambil kebijakan ekonomi, keuangan untuk tujuan agar desa wisata terus maju dan berkembang.

\section{Saran}

1. Untuk aktifitas pengabdian Pengembangan desa wisata, diperlukannya kegiatan marketing yang lebih luas.

2. Pentingnya pembelajaran yang terus menerus/ berkesinambungan sehingga partisipasi dan kerjasama akan terus terpelihara, dan ilmu akuntansi yang diterapkan benar-benar dapat diimplementasikan. 


\section{UCAPAN TERIMAKASIH}

Alhamdulillah puji syukur kami panjatkan kehadirat Allah yang telah memberikan nikmat iman, islam dan kesehatan, sehingga setelah beberapa bulan berjalan kami menjalankan kegitan pengabdian, akhirnya kegiatan ini selesai dengan baik dan akan terus berkelanjutan dalam mwmbngaun desa wisata. Solawat dan salam kami khaturkan ke atas baginda Rasululullah swt, yang telah membuat hidup penuh cinta dan kasih saying, yang membuat hidup kita menjadi bermanfaat, bahagia dunia akherat, Tak lupa saya ucapkan terimakasih yang terhingga kepada LPPM yang telah membimbing dan membantu kami dari materi dan moril. Tak terlupakan juga terimaksih yang takterhingga atas kebaikan pak kepala desa dan masyarakat desa karang MasMAs sehingga proses pengabdian ini dapat berjalan dengan baik.

\section{DAFTAR PUSTAKA}

Al Haryono Yusuf (2011), Dasar-dasar Akuntansi, jilid 2 Cetakan Pertama Desember 2011, Sekolah Tinggi Ekonomi Yayasan Keluarga Pahlawan Negara, Yogyakarta.

Arfan Ikhsan (2009), Pengantar Praktisi Akuntansi, Grahallmu, Yogyakarta.

Carl S Warren, James M. Reeve, Philip E. Fess, (2007), Accounting Pengantar Akuntansi, Salemba Empat, Jakarta.

Ely Suhayatidan Sri Dewi Anggadini (2009), Akuntansi Keuangan, Grahallmu, Yogyakarta

Fandely, C. (2002). Perencanaan Kepariwisataan Alam. Fakultas Kehutanan Universitas Gadjah Mada, Bulaksumur, Yogyakarta.

H. Lili M. Sadeli (2009), Dasar-dasar Akuntansi, Edisi 1 Cetakanke 5, BumiAksara, Jakarta.

Hadiwijoyo, Surya Sakti. (2012). Perencanaan Pariwisata Perdesaan Berbasis Masyarakat (Sebuah Pendekatan Konsep). Yogyakarta:Graha IImu.

Nuryanti, Wiendu (1993)Concept, Perspective and Challenges, makalah bagian

dari Laporan Konferensi Internasional mengenai Pariwisata Budaya. Yogyakarta: Gadjah Mada University 


\section{Jurnal ABDIMAS INDEPENDEN}

Vol. 2, No. 1, Mei 2021

Sofjan Assauri (2016) Strategi Management; Sustainable Competitive Advantages edsi 2, Rajawali Pres, Jakarta

Soemarso S.R. (2010), Akuntansi Suatu Pengantar, Buku 2 (Edisi 5), SalembaEmpat, Jakarta.

https://www.kompasiana.com/ahyarros/599a7e1033649414a9488dc2/desamas-mas-yang-memikat-wisatawan, diakses 21 Februari 2019 Pukul 13.10

http://www.berdesa.com/3-dampak-positif-ekonomi-pengembangandesa wisata/, diakses 21 Februari 2019 Pukul 13.10

P P U A P BPTP JABAR, (20015) Pengembangan Petunjuk Teknis Budidaya Sapi Potong Usaha Agribisnis Pedesaan

Balai Pengkajian Teknoogi Pertanian (Bptp), (2009) Jawa Barat balai Besar Pengkajian Dan Pengembangan Teknologi Pertanian Badan Penelitian Dan Pengembangan Pertanian Departemen Pertanian 